\title{
Effects of Bubbles and Sea Spray on Air-Sea Exchange in Hurricane Conditions
}

\author{
Alexander Soloviev • Roger Lukas
}

Received: 14 November 2008 / Accepted: 4 May 2010 / Published online: 28 May 2010

(C) The Author(s) 2010. This article is published with open access at Springerlink.com

\begin{abstract}
The lower limit on the drag coefficient under hurricane force winds is determined by the break-up of the air-sea interface due to Kelvin-Helmholtz instability and formation of the two-phase transition layer consisting of sea spray and air bubbles. As a consequence, a regime of marginal stability develops. In this regime, the air-sea drag coefficient is determined by the turbulence characteristics of the two-phase transition layer. The upper limit on the drag coefficient is determined by the Charnock-type wave resistance. Most of the observational estimates of the drag coefficient obtained in hurricane conditions and in laboratory experiments appear to lie between the two extreme regimes: wave resistance and marginal stability.
\end{abstract}

Keywords Air-sea interface · Drag coefficient · Hurricane $\cdot$ Kelvin-Helmholtz instability · Marginal stability

\section{Introduction}

Improved understanding of the physical processes near the air-sea interface is required for the development of a better forecast of hurricane strength. Hurricanes extract thermal energy from the ocean, convert it into kinetic energy, and then dissipate a significant fraction of their kinetic energy into the ocean. The strength of the hurricane thus depends on the balance between exchanges of heat and momentum with the ocean (Emanuel 1995). The efficiency of heat energy transfer from the ocean and mechanical energy dissipation in the ocean

\footnotetext{
A. Soloviev $(\varangle)$

Nova Southeastern University’s Oceanographic Center, 8000 North Ocean Drive, Dania Beach, FL 33004, USA

e-mail: soloviev@nova.edu

R. Lukas

Department of Oceanography, University of Hawaii at Manoa, 1000 Pope Road, Honolulu, HI 96822, USA

e-mail: rlukas@hawaii.edu
} 
a

Wind

Air-flow attached to the air-sea interface due to presence of viscous sublayers on the air and water sides of the interface

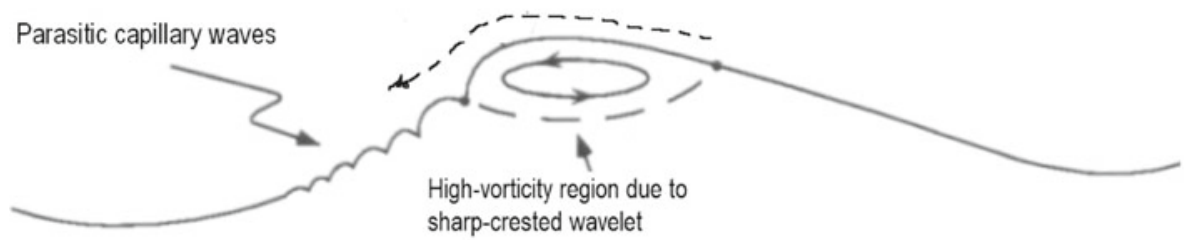

b

Wind

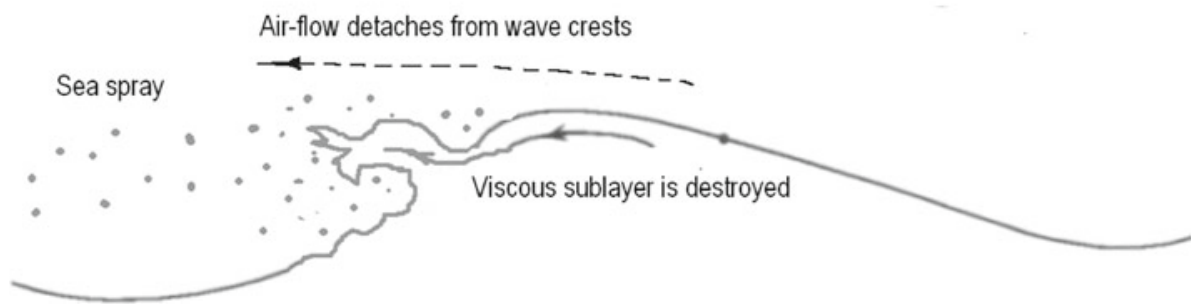

Fig. 1 Microscale wave breaking under a moderate and $\mathbf{b}$ very high wind-speed conditions. A small projection appearing on the downwind slope of the wave near the crest destroys the capillary wave train and aqueous viscous sublayer, which results in the air-flow detachment from waves and the drag reduction. Simultaneously, spume is torn from the wave crest

significantly depends on the structures of the near-surface turbulent boundary layers and the properties of the sea surface.

Under high winds, breaking waves disrupt the air-sea interface producing a two-phase layer-air bubbles in water and sea-spray droplets in air. The sea surface is almost completely covered with the two-phase environment during wind speeds exceeding $25-30 \mathrm{~m} \mathrm{~s}^{-1}$ (Powell et al. 2003; Black et al. 2007). This mixed-phase environment changes the dynamics and thermodynamics of air-sea interaction (Emanuel 2003; Barenblatt et al. 2005; Soloviev and Lukas 2006; Kudryavtsev 2006; Bye and Jenkins 2006).

The air-sea interface is stabilized by the forces of gravity and surface tension. Wind stress and pressure fluctuations disturb the sea surface, while gravity and surface tension restore it, producing surface waves. For light to moderate winds, the upwind wave surface is relatively smooth, but small ripples - capillary waves - are observed on the downwind surface near the crest (Cox 1958). The presence of sharp-crested wavelets results in the development of a high-vorticity area- "roller"- accompanied by a parasitic capillary-wave train (LonguetHiggins 1992). This process leads to "microscale wave breaking" (Banner and Phillips 1974) (Fig. 1a). Microscale wave breaking occurs much more often than the wave breaking resulting in white capping; thus, it is an important mechanism in the momentum transfer between the atmosphere and ocean. It is also an effective mechanism for interfacial gas transfer (Csanady 1990; Jessup et al. 1997). 
Wave breaking that results in white capping and large droplet (spume) generation starts at wind speeds exceeding 7-9 $\mathrm{m} \mathrm{s}^{-1}$ (Andreas 2004). The amount of spume generated during wave breaking, however, is apparently not sufficient to maintain a continuous two-phase environment, unless the wind speed reaches approximately 25-30 $\mathrm{m} \mathrm{s}^{-1}$ (Powell et al. 2003; Black et al. 2007).

Based on laboratory experimentation Koga (1981) suggested that there is a mechanism of direct disruption of the air-sea interface under very high wind speeds, viz. KelvinHelmholtz $(\mathrm{K}-\mathrm{H})$ instability. The $\mathrm{K}-\mathrm{H}$ instability is a rapidly growing type of instability (Thorpe 1969), and the break-up of the air-sea interface due to K-H instability results in the separation of the airflow from the wave crests, which is schematically shown in Fig. 1b. According to Donelan et al. (2004), Kudryavtsev and Makin (2007), Kukulka and Hara (2008), and Mueller and Veron (2009), the air-flow separation may considerably reduce the wave resistance (though not without adding stress in some situations).

According to Koga (1981) and Soloviev and Lukas (2006), the K-H instability of the air-sea interface occurs when the wind speed is achieved for which the speed of surface wind-drift current $U_{\mathrm{s}}$ exceeds the minimum phase speed of gravity-capillary waves, $c_{\min }=$ $0.232 \mathrm{~m} \mathrm{~s}^{-1}$. The threshold for the $\mathrm{K}-\mathrm{H}$ instability at the air-sea interface can therefore be defined by the condition, $U_{\mathrm{s}} / c_{\min }=1$.

The speed of the surface wind drift current is $U_{\mathrm{s}} \approx b u_{* \mathrm{w}}$, where the average value of coefficient $b$ is approximately equal to 16 based on surface drifters measurements (Wu 1975) and 7.4 from infrared imaging (Zhang and Harrison 2004). The latter authors attributed this difference to different experimental methods. In both cases, the value of coefficient $b$ noticeably did not reveal any significant dependence on wind speed (though the wind-speed range up to $12-15 \mathrm{~m} \mathrm{~s}^{-1}$ only was studied). The minimum of the phase speed of gravity-capillary waves is determined by the relation $c_{\min }=\left(4 g \sigma_{\mathrm{s}} / \rho_{\mathrm{w}}\right)^{1 / 4}$ (Phillips 1977).

One can consider the following non-dimensional ratio:

$$
\frac{U_{\mathrm{s}}}{c_{\min }} \approx \frac{b u_{* \mathrm{w}}}{\left(4 g \sigma_{\mathrm{s}} / \rho_{\mathrm{w}}\right)^{1 / 4}}=\frac{b}{2^{1 / 2}} \frac{u_{* \mathrm{a}}\left(\rho_{\mathrm{a}} / \rho_{\mathrm{w}}\right)^{1 / 2}}{\left(g \sigma_{\mathrm{s}} / \rho_{\mathrm{w}}\right)^{1 / 4}} \sim \frac{u_{* \mathrm{a}}}{\left(g \sigma_{\mathrm{s}} \rho_{\mathrm{w}} / \rho_{\mathrm{a}}^{2}\right)^{1 / 4}}=K,
$$

where $u_{* \mathrm{w}}$ is the friction velocity in water, $u_{* \mathrm{w}}=\left(\rho_{\mathrm{a}} / \rho_{\mathrm{W}}\right)^{1 / 2} u_{* \mathrm{a}}$, and $u_{* \mathrm{a}}$ is the friction velocity in air, $\rho_{\mathrm{w}}$ and $\rho_{\mathrm{a}}$ are the water and air densities, respectively, $\sigma_{\mathrm{s}}$ is the surface tension, and $g$ is the acceleration due to gravity.

We call the non-dimensional number,

$$
K=\frac{u_{* \mathrm{a}}}{\left(g \sigma_{\mathrm{s}} \rho_{\mathrm{w}} / \rho_{\mathrm{a}}^{2}\right)^{1 / 4}},
$$

the Koga number. Soloviev and Lukas (2006) introduced a similar number, but due to a misprint, it appeared in a dimensional form. Note that the coefficient $b$ does not enter definition (2).

The $\mathrm{K}-\mathrm{H}$ instability occurs when

$$
K>K_{\mathrm{cr}},
$$

implying that the near-surface wind has accelerated past the point of the critical Koga number. From the laboratory experiments of Koga (1981), an upper estimate of the critical Koga number is $K_{\mathrm{cr}} \approx 0.26$, which corresponds to $u_{* \mathrm{a}}=1.24 \mathrm{~m} \mathrm{~s}^{-1}$ and approximately to a wind speed $U_{10} \approx 30 \mathrm{~m} \mathrm{~s}^{-1}$ at 10 -m height. Note that the estimate of $K_{\mathrm{cr}}$ from Eq. 1 with condition $U_{\mathrm{s}} / c_{\min }=1$ at $b=16$ (following from Wu 1975) results in $K_{\mathrm{cr}} \approx 0.09$, which corresponds 
to $U_{10} \approx 10 \mathrm{~m} \mathrm{~s}^{-1}$. This suggests that sporadic direct disruptions of the air-sea interface may start at wind speeds as low as $10 \mathrm{~m} \mathrm{~s}^{-1}$.

Note that a somewhat similar dimensionless parameter $R_{u}^{1 / 4}=u_{*} /\left(g \sigma_{\mathrm{s}} / \rho_{\mathrm{W}}\right)^{1 / 4}$ was introduced by Emanuel (2003) as a criterion for the lofting of spray by turbulence. Fairall et al. (2009) implemented this parameter in an advanced sea-spray production function.

In this paper, we derive a formulation of the equivalent bulk air-sea drag coefficient in the presence of the two-phase environment. For this purpose, we exploit and further develop the concept of direct disruption of the air-sea interface during very high wind-speed conditions.

In the following, Sect. 2 describes the two-phase transition layer at the air-sea interface in hurricane conditions. Section 3 introduces a hypothesis of self-regulation and regime of marginal stability in the two-phase layer at the air-sea interface; based on this hypothesis we develop a relation for the thickness of the transition layer. Section 3 also provides a discussion of the effect of sea spray and air bubbles outside the two-phase transition layer. Section 4 develops the law of aerodynamic resistance of the two-phase environment, and Sect. 5 gives conclusions.

\section{Kelvin-Helmholtz Instability of the Air-Sea Interface}

The break-up of the air-sea interface in very strong winds leads to the growth of sheets, fingers, and intense droplet and bubble production (Lozano et al. 2001; Yecko et al. 2002). A two-phase environment is formed near the air-sea interface as schematically shown in Fig. 2. The transition layer, once created, is subject to another type of Kelvin-Helmholtz instability due to shear across it.

The following necessary condition for the K-H instability in the two-layer system follows from linear theory (see, Cushman-Roisin and Beckers 2009):

$$
g\left(\rho_{\mathrm{w}}^{2}-\rho_{\mathrm{a}}^{2}\right)<k \rho_{\mathrm{a}} \rho_{\mathrm{w}}\left(U_{\mathrm{a}}-U_{\mathrm{w}}\right)^{2},
$$

where $k$ is the wavenumber of a sinusoidal perturbation (corresponding to wavelength $2 \pi / k$ ). The non-linear development of the instability is likely to be related to the initial linear instability (Lefebvre 1989; Lasheras and Hopfinger 2000). The most rapidly growing mode of the linear $\mathrm{K}-\mathrm{H}$ instability in a two-layer system is determined from the relationship (Miles and Howard 1964):

$$
k H \approx m .
$$

Fig. 2 Self-regulating state of the air-sea interface layer (regime of marginal stability)
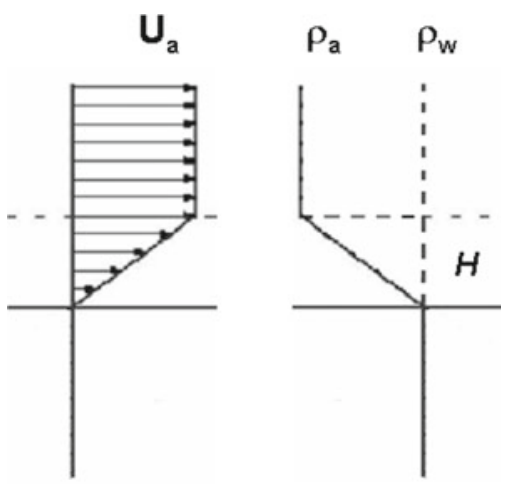
where $H$ is the mixing layer thickness formed as a result of the $\mathrm{K}-\mathrm{H}$ instability, and $m \approx 0.8$, which is consistent with the Cushman-Roisin and Beckers (2009) order of magnitude estimate $m \sim 1$ but requires future validation.

Instability criterion (4) can be expressed as,

$$
R i_{*}<m R i_{\mathrm{cr}}
$$

where

$$
\begin{gathered}
R i_{*}=g \frac{H\left(\rho_{\mathrm{w}}-\rho_{\mathrm{a}}\right)}{\rho\left(U_{\mathrm{w}}-U_{\mathrm{a}}\right)^{2}}, \\
\rho=\frac{\rho_{\mathrm{a}} \rho_{\mathrm{w}}}{\left(\rho_{\mathrm{a}}+\rho_{\mathrm{w}}\right) / 2},
\end{gathered}
$$

where $R i_{\mathrm{cr}}$ is the critical value of $R i, \rho_{\mathrm{w}}$ and $\rho_{\mathrm{a}}$ are bulk densities, and $U_{\mathrm{w}}$ and $U_{\mathrm{a}}$ are velocities for water and air at the lower and upper boundaries of the transition layer, respectively.

Remarkably, Eq. 4 is applicable to the air-sea interface where the density change is not small, because this equation is not limited by the Boussinesq approximation requiring small density changes. Note that, under the Boussinesq approximation and linear velocity and density profiles, $R i$ defined here via Eqs. 7-8 transforms into the conventional gradient Richardson number.

For a two-layer system, it follows from Eqs. 4-8 that $R i_{\mathrm{cr}}=1 / 2$. However, the theoretical analysis by Cushman-Roisin (1994) and Cushman-Roisin and Beckers (2009) for a three-layer system including a transition layer with linear profiles of velocity and density resulted in $R i_{\text {cr }}=1 / 4$. The difference in $R i_{\text {cr }}$ between discontinuous and linear density and velocity profiles can be explained by the consumption of kinetic energy by vertical motions for the case of a continuous environment. This is also consistent with the fact that $R i_{\text {cr }}=$ $1 / 2$ refers to the onset of the instability, while $R i_{\mathrm{cr}}=1 / 4$ corresponds to complete mixing (Gramer 2007; Cushman-Roisin and Beckers 2009).

It should be noted that the surface tension, which is a determining parameter in the formulation for the Koga number, does not enter Eq. 4. Indeed, after the disruption of the sea surface and formation of the transition layer, surface tension is no longer a relevant parameter because the clearly defined interface does not exist. The surface tension effects are still important for air bubbles and spray droplets constituting the transition layer (though at the smaller-size end of their size spectra only).

The maximum thickness of the transition layer can be estimated from Eqs. 7-8 and condition $R i_{*}=m R i_{\text {cr }}$ as follows:

$$
H=2 m R i_{\mathrm{cr}} \frac{\rho_{\mathrm{a}}}{\rho_{\mathrm{w}}} \frac{\Delta U^{2}}{g},
$$

where $\Delta U$ is the velocity difference across the transition layer. Here we make use of the fact that $\rho_{\mathrm{w}} \gg \rho_{\mathrm{a}}$. In Eq. 9, we have ignored the velocity gradient both below and above the transition layer. We, however, take into account the velocity profile outside the transition layer in Sect. 4. 


\section{Self-Regulating State of the Air-Sea Interface Layer}

\subsection{Regime of Marginal Stability}

The equilibrium thickness $H$ of the transition layer at the air-sea interface schematically shown in Fig. 2 is determined by the balance between mixing in the transition layer due to $\mathrm{K}-\mathrm{H}$ instability and the gravity force acting on the immiscible environment consisting of bubbles and droplets. Due to mixing, the thickness of the transition layer tends to increase with time by entraining and fragmenting water and air parcels from outside the transition layer; however, as soon as it exceeds $H$, the necessary condition for $\mathrm{K}-\mathrm{H}$ instability (6) is no longer satisfied, and the mixing ceases. The gravity force acting on bubbles and droplets tends to shrink the transition layer and, with time, to reduce its thickness below $H$, thus restoring condition (6) leading to the $\mathrm{K}-\mathrm{H}$ instability and new mixing within the transition layer. This cycle continuously repeats, maintaining the transition-layer thickness near $H$.

Turner (1973) defined the self-regulating state as a marginally stable regime of the flow near the critical value of the gradient Richardson number. Development of a self-regulating state has been observed under certain environmental conditions (strong stable stratification and shear) in laboratory and natural flows (Turner 1973; Neuwstadt 1984; Kudryavtsev and Soloviev 1988). According to Turner's similarity theory for the stratified turbulent boundary layer, in the self-regulating state of the flow the local gradients of density $\partial_{z} \rho$ and velocity $\partial_{z} u$ depend on acceleration due to gravity $(g)$ and density $(\Delta \rho)$ and velocity $(\Delta u)$ differences across the boundary layer. From dimensional considerations, under this approximation the velocity and density profiles can only be linear because the set of determining parameters does not include any length scale.

The Turner (1973) similarity theory is expected to be applicable to the two-phase transition layer, and it is notable that this theory does not require the Boussinesq approximation. Note that in the situation shown in Fig. 2, the distance from the air-sea interface is no longer a determining parameter, because the interface is no longer defined.

Turner (1973) reported experimental values of the critical Richardson number $R i_{\text {cr }}$ between 0.05 and 0.1 from observations in laboratory and natural flows. Kudryavtsev and Soloviev (1988) reported $R i_{\text {cr }} \approx 0.3$ from observations of the marginal stability regime in the slippery near-surface layer of the ocean arising due to diurnal warming. These numbers, however, refer to situations with relatively small density differences.

\subsection{The Effects of Sea Spray and Air Bubbles Outside the Transition Layer}

There are three mechanisms of sea-spray production at the air-sea interface: (1) bursting of entrained air bubbles, (2) splashing, and (3) tearing water from the wave crest. The first mechanism creates film and jet droplets, which are relatively small, while the third mechanism is responsible for the production of larger droplets - spume - that fall to the sea surface and create smaller droplets by splashing. Plunging wave crests also create splash droplets and air bubbles. The third mechanism dominates the bubble and spray production in hurricane conditions (Koga 1981). Based on his laboratory experiments, Koga (1981) attributed the third mechanism to the disruption of the air-sea interface due to the $\mathrm{K}-\mathrm{H}$ instability. According to our estimates in Sect. 1, sporadic K-H instability events may commence at $U_{10} \approx 10 \mathrm{~m} \mathrm{~s}^{-1}$.

The rate of spray generation rapidly increases with wind speed (Andreas 2004), though only relatively small spray droplets are entrained by the turbulent air flow. Larger droplets tend to fall back into the water (into the transition layer in our model) due to relatively large 
Fig. 3 Schematic representation of the velocity profile in the atmospheric log layer $\left(H, h_{10}\right)$, two-phase transition layer $(0, H)$, wave-stirred near-surface layer $\left(-H_{\mathrm{S}}, 0\right)$, and turbulence-diffusion layer $\left(<-H_{\mathrm{S}}\right)$

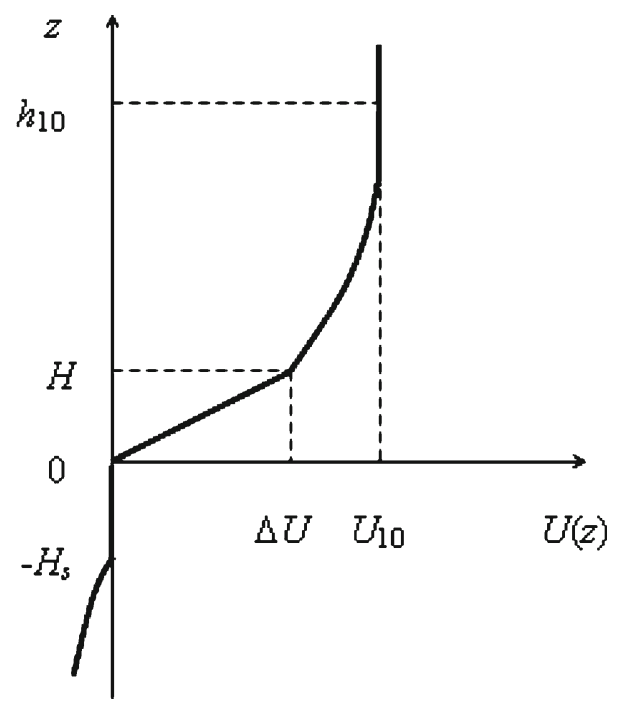

terminal velocities (Soloviev and Lukas 2006). The largest droplets (spume) therefore elude detection during the measurements conducted at some distance from the sea surface, which results in a possible substantial underestimation in the contribution of large droplets in the known sea-spray generation functions.

Buoyancy effects of the spray outside the relatively thin transition layer on the air-sea drag coefficient depend on the spray generation rate and size distribution. Estimates provided in Soloviev and Lukas (2006) suggest that, in the framework of existing sea-spray generation functions (see e.g., Andreas 2004), the buoyancy effect of the spray outside the transition layer alone is not sufficient to explain capping of the drag coefficient in hurricane conditions.

Below the transition layer, there is a wave-stirred layer schematically shown in Fig. 3. The thickness of the wave-stirred layer is of the order of one significant wave height $H_{\mathrm{s}}$ (Terray et al. 1996; Benilov and Ly 2002; Soloviev and Lukas 2003), which is much larger than the thickness of the two-phase transition layer $H$ as estimated from (8).

The effect of air-bubble buoyancy on turbulence is not expected to produce any significant contribution in the average current velocity profile in the wave-stirred layer (Kudryavtsev et al. 2008). A moderate increase of shear due to the effect of air-bubble buoyancy is possible in the turbulence-diffusion layer located below the wave-stirred layer. The effect of bubbles on the average current velocity profile in the turbulence-diffusion layer also appears to be too small to produce any significant contribution to the air-sea drag coefficient in our model.

\section{Resistance Law for the Regime of Marginal Stability}

Figure 3 schematically shows the atmospheric logarithmic boundary layer, the transition layer, the wave stirred layer, and the turbulence diffusion layer. The linear velocity profile in the transition layer resembles the velocity profile in the viscous sublayer of a turbulent flow near a smooth wall (see, e.g., Van Driest 1956). This analogy will be employed here to derive a formulation of the equivalent bulk air-sea drag coefficient in the two-phase environment under strong winds. 
Near a smooth flat surface, the surface roughness length scale is $z_{0} \approx 0.11 v / u_{*}$, while the thickness of the viscous sublayer $\delta_{v} \approx \tilde{c} v / u_{*}$, where $\tilde{c} \approx 5,11$, or 30 for definitions using viscous, log-linear match, or a buffer-zone boundary respectively (see, e.g., Tennekes and Lumley 1972; Hinze 1975). The coefficient $c$ defined as $c=z_{0} / \delta_{v} \approx 0.11 / \tilde{c}$ is then approximately equal to $0.022,0.01$, or 0.0037 , respectively. We use these estimates of $c$ for subsequent drag-coefficient estimates.

In application to the air-sea interface in hurricane conditions, the value of the drag coefficient with respect to the bulk of water (wave-stirred layer) is important. We have therefore introduced in Fig. 3 a coordinate system referenced to the bottom of the two-phase transition layer. The sea surface is no longer defined but the boundaries of the two-phase transition layer can be defined, allowing us to use the lower boundary of the two-phase layer as a reference surface for calculation of the air-sea drag coefficient.

The velocity difference across the aqueous viscous sublayer is critical for triggering the initial $\mathrm{K}-\mathrm{H}$ instability (determined by the Koga number), but is nevertheless irrelevant after the two-phase transition layer becomes established. The inertial current velocity, which can easily reach $1 \mathrm{~m} \mathrm{~s}^{-1}$ under hurricane forcing, is still much less than the wind speed. For the purpose of the estimation of the drag coefficient at the air-sea interface we therefore ignore any velocity differences in the water below the transition layer.

Interaction of waves with inertial currents can significantly influence the air-sea drag coefficient and momentum exchange in hurricanes (Fan et al. 2009). However, our model is aimed at the estimation of the lower limit of the drag coefficient in hurricane conditions due to a two-phase environment. Merging this parameterization with the wave parameterizations is the subject of future work.

A system of equations representing the situation shown in Fig. 3 is as follows:

$$
\begin{aligned}
U_{10} & =\frac{u_{* \mathrm{a}}}{\kappa} \ln \frac{h_{10}+z_{0}}{z_{0}}, \\
\Delta U & =\frac{u_{* \mathrm{a}}}{\kappa} \ln \frac{H+z_{0}}{z_{0}}, \\
u_{* \mathrm{a}} & =C_{10}^{1 / 2} U_{10}, \\
H & =2 m R i_{\mathrm{cr}} \frac{\rho_{\mathrm{a}}}{\rho_{\mathrm{w}}} \frac{\Delta U^{2}}{g}, \\
z_{0} & =c H,
\end{aligned}
$$

where $U_{10}$ is the wind speed at a nominal $10-\mathrm{m}$ height, $h_{10}$ is the height of the wind-speed measurement, which is traditionally taken to be $10 \mathrm{~m}, C_{10}$ is the respective drag coefficient, $z_{0}$ is the surface roughness length, $c$ is the dimensionless coefficient connecting the surface roughness length $z_{0}$ and the thickness of the transition layer $H, g$ is the acceleration due to gravity, and $\kappa$ is the von Karman constant $(\kappa=0.4)$.

Equations 10 and 11 follow from the logarithmic wind speed profile in the air above the transition layer. Equation 12 is the expression of the friction velocity via the air-sea drag coefficient and wind speed at 10-m level. Equation 13 immediately follows from Eq. 9 and the logarithmic profile of wind speed above the transition layer. Equation 14 defines the surface roughness length as a portion of the transition-layer thickness. Based on the above-mentioned analogy of the vertical velocity profile shown in Fig. 3 with that in the logarithmic boundary layer and viscous sublayer near a wall, we assume that $c$ is between 0.022 and 0.0037 . Note that the origin of the coordinate system is taken here as the base of the transition layer, since practical applications require estimation of drag coefficient with respect to the bulk water. 


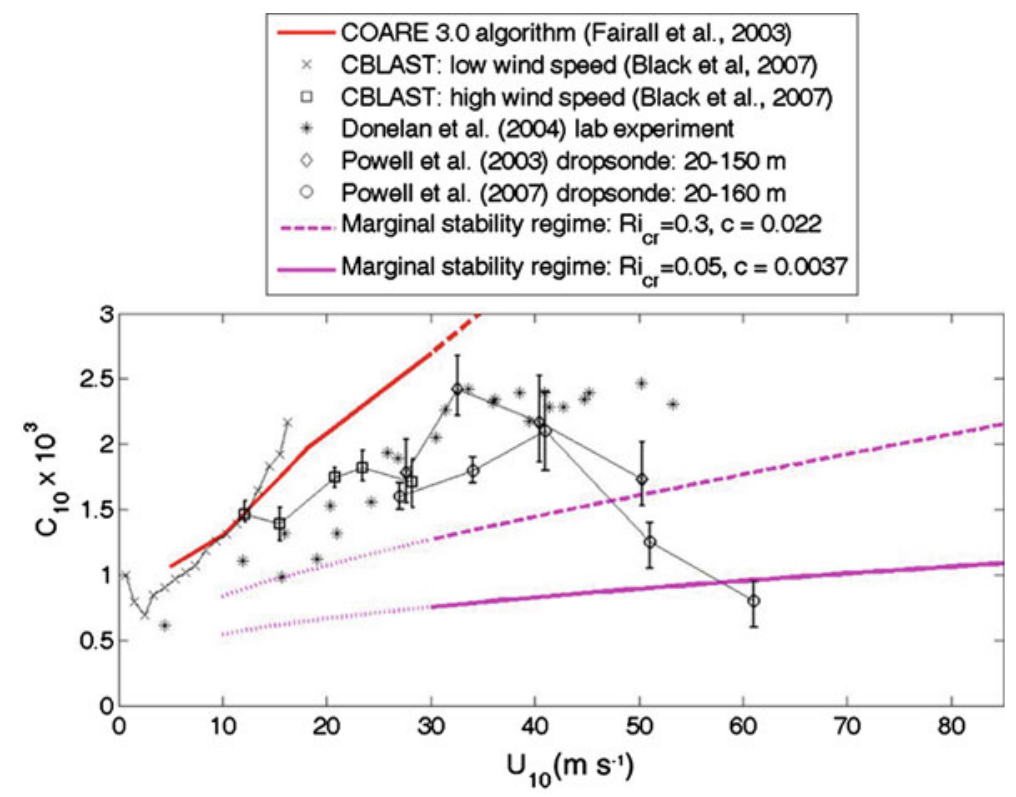

Fig. 4 Comparison of the available field and laboratory data on the air-sea drag coefficient with the traditional (COARE 3.0) and "marginal stability" parameterizations. COARE stands for the Tropical Ocean Global Atmosphere Coupled Ocean-Atmosphere Response Experiment (Webster and Lukas 1992); CBLAST, for the Coupled Boundary Layers Air-Sea Transfer Defense Research Initiative (Black et al. 2007)

The system of Eqs. 10-14 can be reduced to a single transcendental equation for $C_{10}$,

$$
C_{10}=\kappa^{2} / \ln ^{2}\left\{1+h_{10} /\left(2 m R i_{\mathrm{cr}} c \frac{\rho_{\mathrm{a}}}{\rho_{\mathrm{w}}} \frac{U_{10}^{2}}{g} \frac{C_{10}}{\kappa^{2}} \ln ^{2}\left(1+\frac{1}{c}\right)\right)\right\}
$$

which can be solved numerically, giving $C_{10}$ as a function of the wind speed, $U_{10}$. The solution is shown in Fig. 4 as the 'marginal stability regime' curve for two values of $R i_{\text {cr }}$. This solution represents the regime of marginal stability in the two-phase transition layer at the air-sea interface. The dotted portions of the two curves for $U_{10}<30 \mathrm{~m} \mathrm{~s}^{-1}$ correspond to sporadic instability events, when the two-phase coverage is incomplete.

Analysis of Eq. 15 shows that $R i_{\text {cr }}$ and $c$ enter as a product $R i_{\mathrm{cr}} c \ln ^{2}\left(1+c^{-1}\right)$. In Fig. 4 , the marginal stability parameterization derived from solving Eq. 14 is shown for $m=0.8$ and two extreme values of the critical Richardson number, $R i_{\mathrm{cr}}=0.3$ and $R i_{\mathrm{cr}}=0.05$, which have previously been reported from observations of the marginal stability regime in different fluid mechanical problems (see Sect. 3.1). Using the corresponding maximum and minimum values of $c=0.022$ and $c=0.0037$ ensures that the full range of variability due to the sensitivity of $C_{10}$ on $R i_{\text {cr }}$ and $c$ is enclosed between the two curves. The thickness of the two-phase transition layer $H$ calculated from Eqs. 10-14 is relatively small: for $\Delta U$ from 30 to $85 \mathrm{~m} \mathrm{~s}^{-1}$, it ranges from approximately $1 \mathrm{~mm}$ to $0.1 \mathrm{~m}$ at $R i_{\mathrm{cr}}=1 / 4$ and $m=0.8$.

According to Fig. 4, transition to the regime of marginal stability implies a significant decrease in the drag coefficient at approximately $30 \mathrm{~m} \mathrm{~s}^{-1}$ wind speed with its relatively slow subsequent increase at higher wind speeds. The two-phase transition layer takes part of its momentum from the wind, which results in a slow increase of the drag coefficient with wind speed. A similar effect was anticipated by Andreas (2004) though based on a different 
(heuristic) model involving sea spray outside the transition layer. Most of the observational data presented in Fig. 4 (Powell et al. 2003; Donelan et al. 2004; Powell 2007; Black et al. 2007) are concentrated between the COARE 3.0 (Fairall et al. 2003) and marginal stability (this work) parameterizations.

Note that conditions (3) and (6) together can lead to hysteresis. In principle, condition (6) can be satisfied even below the wind speed corresponding to the critical value of the Koga number according to (3). This means that the response of the air-sea interface to external forcing depends not only on the present wind speed but also on the previous history of the system. Expressed mathematically, the response to the external forcing is a doubled-valued function; one value applies when the wind speed is increasing, the other applies when the wind speed is decreasing.

Thus, the presence of hysteresis may extend the spume generation in the regime of marginal stability below the $30 \mathrm{~m} \mathrm{~s}^{-1}$ wind-speed threshold. Moreover, such hysteresis in combination with wind gustiness can explain the patchiness of the areas of spume generation under these wind-speed conditions.

Air-flow separation reduces the wave-induced stress, but not without adding stress due to separation and breaking (see e.g. Kudryavtsev and Makin 2001, 2007; Makin and Kudryavtsev 2002; Kukulka et al. 2007; Kukulka and Hara 2008; Mueller and Veron 2009). Furthermore, the state of the sea surface in hurricane conditions varies in azimuth and distance from the hurricane centre because of the variation in swell characteristics relative to the wind direction (Powell 2007). The relative contribution of the wave and two-phase layer mechanisms to the drag coefficient is also expected to vary. Development of a parameterization taking into account the impact of both mechanisms is a future task, which is important for the realistic representation of the air-sea interface in hurricane models.

\section{Conclusions}

In our model, the direct disruption of the air-sea interface at very high wind speeds results in detachment of the air flow from the wave crests and reduction of the drag coefficient. In our previous work (Soloviev and Lukas 2006), we introduced the Koga number as the criterion for this type of instability at the air-sea interface. The Koga number characterizes the ratio between the velocity difference across the aqueous viscous sublayer and the minimum phase speed of gravity capillary waves, which takes into account surface tension and gravity forces that work to prevent the air-sea interface from disruption. The upper estimate of the critical value of the Koga number, based on the Koga (1981) laboratory experiment, occurs at a wind speed of approximately $30 \mathrm{~m} \mathrm{~s}^{-1}$, which correlates with a Category 1 hurricane. The estimate using the $\mathrm{Wu}$ (1975) relation for the surface wind drift results in a critical Koga number corresponding to a wind speed as low as $10 \mathrm{~m} \mathrm{~s}^{-1}$. Within the wind-speed range from 10 to $30 \mathrm{~m} \mathrm{~s}^{-1}$ the $\mathrm{K}-\mathrm{H}$ instability is sporadic; spume generation is not sufficient to cover the sea surface completely and to maintain a continuous two-phase environment. In the two-phase transition layer formed after the disruption of the air-sea interface, a second type of $\mathrm{K}-\mathrm{H}$ instability provides the mechanism for maintaining the regime of marginal stability in the transition layer. The $\mathrm{K}-\mathrm{H}$ instability in the transition layer no longer directly depends on the surface tension and is determined by the shear and buoyancy forces.

Since the initial $\mathrm{K}-\mathrm{H}$ instability and subsequent $\mathrm{K}-\mathrm{H}$ instability in the transition layer are driven by different physical factors, hysteresis is possible in this system. The hysteresis in combination with gustiness may result in a statistical widening of the wind-speed range in 
which the regime of marginal stability can be observed. The main effect of the two-phase environment on the air-sea drag coefficient is associated with a relatively thin transition layer. Consideration of the regime of marginal stability in the transition layer results in a new type of parameterization for the lower limit on the air-sea drag coefficient in hurricane conditions. This parameterization implies a significant decrease in the drag coefficient at wind speeds of $\approx 30 \mathrm{~m} \mathrm{~s}^{-1}$ with its relatively slow subsequent increase at higher wind speeds. The observational data on the drag coefficient lie between traditional parameterizations and the marginal stability parameterization developed herein.

Development of a parameterization taking into account the impact of the air-flow separation from waves and the two-phase transition layer is an important future task for the realistic representation of the air-sea interface in hurricane models.

Acknowledgements The authors are grateful to Vladimir Kudryavtsev (Nansen Environmental and Remote Sensing Center) and Mark Donelan (University of Miami Rosenstiel School of Marine and Atmosphere Science) for discussions of the problem of air-sea interactions under high wind-speed conditions. Alexander Soloviev acknowledges support from the Nova Southeastern University Oceanographic Center project 'Hydrodynamics and remoter sensing of far wakes of ships'. Roger Lukas has been supported by National Science Foundation grant OCE-0752606.

Open Access This article is distributed under the terms of the Creative Commons Attribution Noncommercial License which permits any noncommercial use, distribution, and reproduction in any medium, provided the original author(s) and source are credited.

\section{References}

Andreas EL (2004) Spray stress revisited. J Phys Oceanogr 34:1429-1440

Banner ML, Phillips OM (1974) On the incipient breaking of small scale waves. J Fluid Mech 65:647-656

Barenblatt GI, Chorin AJ, Prostokishin VM (2005) A note concerning the Lighthill "sandwich model" of tropical cyclones. Proc Natl Acad Sci USA 102(32):1148-1150

Benilov AY, Ly LN (2002) Modeling of surface waves breaking effects in the ocean upper layer. Math Comput Model 35:191-213

Black PG, D'Asaro EA, Drennan WM, French JR, Niiler PP, Sanford TB, Terrill EJ, Walsh EJ, Zhang JA (2007) Air-sea exchange in hurricanes: synthesis of observations from the coupled boundary layer air-sea transfer experiment. Bull Am Meteorol Soc 88(3):357-374

Bye JAT, Jenkins AD (2006) Drag coefficient reduction at very high wind speeds. J Geophys Res 111. doi:10. 1029/2005JC003114

Cox CS (1958) Measurements of slopes of high-frequency wind waves. J Mar Res 16:199-225

Csanady GT (1990) The role of breaking wavelets in air-sea gas transfer. J Geophys Res 95:749-759

Cushman-Roisin B (1994) Introduction to geophysical fluid dynamics. Prentice-Hall, New Jersey, 290 pp

Cushman-Roisin B, Beckers J-M (2009) Introduction to geophysical fluid dynamics: physical and numerical aspects. Academic Press (in press)

Donelan MA, Haus BK, Reul N, Plant W, Stiassnie M, Graber H, Brown O, Saltzman E (2004) On the limiting aerodynamic roughness of the ocean in very strong winds. Geophys Res Lett 31:L18306

Emanuel KA (1995) Sensitivity of tropical cyclones to surface exchange coefficients and a revised steady-state model incorporating eye dynamics. J Atmos Sci 52:3969-3976

Emanuel K (2003) A similarity hypothesis for air-sea exchange at extreme wind speeds. J Atmos Sci 60: $1420-1428$

Fairall CW, Bradley EF, Hare JE, Grachev AA, Edson JB (2003) Bulk parameterization of air- sea fluxes: updates and verification for the COARE algorithm. J Clim 16:571-591

Fairall CW, Banner ML, Peirson WL, Asher W, Morison RP (2009) Investigation of the physical scaling of sea spray spume droplet production. J Geophys Res 114:C10001. doi:10.1029/2008JC004918

Fan Y, Ginis I, Hara T (2009) The effect of wind-wave-current interaction on air-sea momentum fluxes and ocean response in tropical cyclones. J Phys Oceanogr 39:1019-1034

Gramer L (2007) Kelvin-Helmholtz Instabilities. GFD II, 32 pp. http://www.rsmas.miami.edu/users/ isavelyev/GFD-2/KH-I.pdf

Hinze J (1975) Turbulence. McGraw-Hill, New York, 790 pp 
Jessup AT, Zappa CJ, Yeh HH (1997) Defining and quantifying microscale wave breaking with infrared imagery. J Geophys Res 102(C10):23145-23154

Koga M (1981) Direct production of droplets from breaking wind-waves—its observation by a multi-colored overlapping exposure technique. Tellus 33:552-563

Kudryavtsev VN (2006) On the effect of sea drops on the atmospheric boundary layer. J Geophys Res 111:C07020. doi:10.1029/2005JC002970:1-18

Kudryavtsev VN, Makin VK (2001) The impact of air-flow separation on the drag of the sea surface. Boundary-Layer Meteorol 98:155-171

Kudryavtsev VN, Makin VK (2007) Aerodynamic roughness of the sea surface at high winds. Boundary-Layer Meteorol 125:298-303

Kudryavtsev VN, Soloviev AV (1988) Daytime near-surface current. Dokl Akad Nauk SSSR 303(1):59-62

Kudryavtsev V, Dulov V, Shira V, Malinovsky V (2008) On vertical structure of wind-driven sea surface currents. J Phys Oceanogr 38(10):2121-2144

Kukulka T, Hara T (2008) The effect of breaking waves on a coupled model of wind and ocean surface waves. Part II: growing seas. J Phys Oceanogr 38:2164-2184

Kukulka T, Hara T, Belcher SE (2007) A model of the air-sea momentum flux and breaking-wave distribution for strongly forced wind waves. J Phys Oceanogr 37:1811-1828

Kundu P (1990) Fluid mechanics. Academic Press, San Diego, 638 pp

Lasheras JC, Hopfinger EJ (2000) Liquid jet instability and atomization in a coaxial jet stream. Ann Rev Fluid Mech 32:275

Lefebvre AH (1989) Atomization and spray. Hemisphere, New York, 421 pp

Longuet-Higgins MS (1992) Capillary rollers and bores. J Fluid Mech 240:659-679

Lozano A, Barreras F, Hauke G, Dopazo C (2001) Longitudinal instabilities in an airblasted liquid sheet. J Fluid Mech 437:143-173

Makin VK, Kudryavtsev VN (2002) Impact of dominant waves on sea drag. Boundary-Layer Meteorol 103: 83-99

Miles JW, Howard LN (1964) Note on a heterogeneous shear flow. J Fluid Mech 20:331-336

Mueller JA, Veron F (2009) Nonlinear formulation of the bulk surface stress over breaking waves: feedback mechanisms from air-flow separation. Boundary-Layer Meteorol 130:117-134

Neuwstadt FTM (1984) The turbulent structure of the stable, nocturnal boundary layer. J Atmos Sci 41: 2202-2216

Phillips OM (1977) The dynamics of the upper ocean. Cambridge University Press, UK, 366 pp

Powell MD (2007) New findings on hurricane intensity, wind field extent, and surface drag coefficient behavior. In: Tenth international workshop on wave hindcasting and forecasting and coastal hazard symposium, North Shore, Oahu, Hawaii, November 11-16, 2007, 14 pp

Powell MD, Vickery PJ, Reinhold TA (2003) Reduced drag coefficient for high wind speeds in tropical cyclones. Nature 422:279-283

Soloviev AV, Lukas R (2003) Observation of wave-enhanced turbulence in the near-surface layer of the ocean during TOGA COARE. Deep-Sea Res I 50:371-395

Soloviev A, Lukas R (2006) The near-surface layer of the ocean: structure, dynamics, and applications. Springer, New York, 572 pp

Tennekes H, Lumley JL (1972) A first course in turbulence. MIT Press, MA, 300 pp

Terray EA, Donelan MA, Agrawal YC, Drennan WM, Kahma KK, Williams AJ III, Hwang PA, Kitaigorodskii SA (1996) Estimates of kinetic energy dissipation under breaking waves. J Phys Oceanogr 26:792-807

Thorpe S (1969) Experiments on the instability of stratified shear flows: immiscible fluids. J Fluid Mech 39:25-48

Turner JS (1973) Buoyancy effects in fluids. Cambridge University Press, New York, 382 pp

Van Driest ER (1956) On turbulent flow near a wall. J Aero Sci 23:1007-1010

Webster PJ, Lukas R (1992) TOGA COARE: The Coupled Ocean-Atmosphere Response Experiment. Bull Am Meteorol Soc 73:1377-1416

Wu J (1975) Wind-induced drift current. J Fluid Mech 68:49-70

Yecko P, Zaleski S, Fullana J-M (2002) Viscous modes in two-phase mixing layers. Phys Fluids 14:4115-4122

Zhang X, Harrison S (2004) A laboratory observation of the surface temperature and velocity distributions on a wavy and windy air-water interface. Phys Fluids 16:L5-L8 